\title{
Parasites on an intertidal Corophium-bed: factors determining the phenology of microphallid trematodes in the intermediate host populations of the mud-snail Hydrobia ulvae and the amphipod Corophium volutator
}

\author{
Kim N. Mouritsen, Tomas Jensen \& K. Thomas Jensen \\ Department of Marine Ecology, Institute of Biological Sciences, University of Aarhus, Finlandsgade 14, \\ DK-8200 Aarhus N, Denmark \\ (Phone: [+45] 8942 4386; Fax: [+45]8942 4395; e-mail: KNM@bio.aau.dk)
}

Key words: Corophium, Hydrobia, intertidal mud flats, microphallid trematodes, phenology

\begin{abstract}
The phenology of microphallid trematodes within their intermediate host populations has been studied on an intertidal mud flat. The parasites use the mud snail Hydrobia ulvae and the infaunal amphipod Corophium volutator as first and secondary intermediate host, respectively. Migratory shorebirds act as final hosts. Our results show a general trend of decline in the density of infected intermediate hosts during both spring and autumn, which could mainly be ascribed to shorebird predation. During summer the density of both infected snails and infected amphipods increased considerably, with a culmination in June within the snail population (1000 infected $\left.\mathrm{m}^{-2}\right)$ and in August within the amphipod population (40000 infected $\mathrm{m}^{-2}$ ). This time lag in parasite occurrence could be related to (1) the development time of larval trematodes within the snails, (2) higher ambient temperatures in late summer increasing parasite transmission between snails and amphipods during this period, and (3) a general increase in the Corophium population during late summer. From samples collected between 1990 and 1995 it is shown that microphallid trematodes occasionally may give rise to mass mortality in the amphipod population. The prerequisites for such an event are a high parasite prevalence within the first intermediate host population and unusually high ambient temperatures, facilitating parasite transmission to the secondary intermediate host, C. volutator.
\end{abstract}

\section{Introduction}

Considering a community of infaunal macro invertebrates at an intertidal mud flat, an array of reasons why a given species should show wide fluctuations in abundance can be given. Among the well-known factors the often harsh environmental conditions that prevail in tidal areas can be mentioned, e.g. prolonged and strong offshore winds causing desiccation, strong onshore winds causing substrate erosion, thermal and osmotic stress during low water and mechanical stress due to ice pack during winter at higher latitudes (Reise, 1985; Barnes \& Hughes, 1988; Nybakken, 1993). However, also biotic factors may have profound influence on the population dynamics of intertidal softbottom organisms. For instance, well-defined periods of recruitment usually result in substantial increases in abundance of many benthic organisms, whereas seasonality in the often very significant predation pressure from fish, shorebirds and other epibenthic and infaunal predators may cause sudden declines in density of many infaunal organisms, including $C$. volutator (Reise, 1985; Posey, 1987; Peer et al., 1986; Ambrose, 1991; Wilson, 1991).

However, one biotic factor only very rarely considered in ecological studies of softbottom macrozoobenthic communities is parasitism. In the light of the growing body of evidence emphasizing parasites as more or less cryptic determinants of host population dynamics and even community structure (Dobson \& Hudson, 1986; Anderson, 1991; Minchella \& Scott, 1991; Holt, 1993), and given that most if not all soft- 
bottom macro invertebrates are hosts of one or usually more species of parasites (Kinne, 1980; Sousa, 1991), the lack of attention to the ecological consequences of parasitism is unfortunate.

An initial step in achieving more information about the parasites' effect on their host population is to obtain knowledge of the phenology of the parasites themselves in order to identify factors controlling their abundance. The present study aimed at describing the phenology of parasites in their intermediate host populations of the mud snail Hydrobia ulvae (Pennant) and the tube-dwelling amphipod Corophium volutator (Pallas). The life cycle of the microphallid digenean trematodes Maritrema subdolum Jägerskiöld, 1909 and Microphallus claviformis (Brandes, 1888) on intertidal mud flats is used as a model. Special reference is given to the parasites' influence on the population dynamics of Corophium. Hydrobia and Corophium are both widely distributed and abundant on intertidal mud flats, and hence, can be considered central macro-zoobenthic organisms in the softbottom intertidal ecosystem.

\section{Materials and methods}

\section{The microphallid life cycle}

The two species of microphallid trematodes have a similar but rather complex life cycle (Figure 1). The adult parasites reproduce sexually in the digestive tract of their final vertebrate hosts, being various shorebirds. Their eggs are expelled to the exterior through the droppings of the birds. Left on the sediment surface, some of these eggs may be eaten (probably accidentally) by the first intermediate host, Hydrobia spp. Within the gonads of the snails, the parasites reproduce asexually and develop into sporocysts that upon the right stimuli proliferate myriads of tail-carrying cercariae. The cercariae then seek out and penetrate the cuticle of the secondary intermediate amphipod host, in the Wadden Sea usually Corophium spp. Within the body cavity of the amphipods the now tail-less cercariae encyst as metacercariae that gradually develop into adult trematode worms. The life cycle is completed when the infected Corophium specimen is eaten by a suitable shorebird host.

\section{The study site}

As study site we selected a mid-tidal station on an approximately 80 ha large Corophium-bed at Højer tidal flat (approximately $1500 \mathrm{~m}$ intertidal zone) in the southern part of the Danish Wadden Sea (Figure 2). At low water, a Corophium-bed is often characterized by a mosaic of alternating tidal pools and emerged areas (Figure 3 ). The latter supports very high numbers of amphipods, whereas considerably fewer specimens occur in the pools. The mud snail H. ulvae can be found abundantly on both the emerged areas and in the pools. The Corophium-bed is very attractive to feeding waders, especially the Dunlin Calidris alpina, which in this area occur at average densities above 200 foraging birds per hectare during the autumn and spring migration periods (Mouritsen, 1994).

\section{Collection and treatment of animals}

At each sampling event, five to ten core samples $\left(50 \mathrm{~cm}^{2}, 25 \mathrm{~cm}\right.$ deep) were collected on the emerged areas of the Corophium-bed and sieved on location through a $500 \mu \mathrm{m}$ mesh sieve. Retained animals were preserved in $\mathrm{pH}$-buffered $4 \%$ formaldehyde. In the laboratory densities were calculated and the length of the amphipods was measured from rostrum to telson. Snails and amphipods were subsequently dissected and examined for the presence of microphallid trematodes. Parasites were identified in accordance with Deblock (1980), Lauckner (1987) and own unpublished experimental results regarding identification of metacercariae in the amphipods.

Measurements and dissection were carried out on animals from unbiased subsamples at each sampling occasion (Hydrobia: 33-220 specimens; Corophium: 102-150 specimens).

\section{Analysis and presentation of data}

Regarding the main phenological description (Figure 4), the data originate from seven sampling occasions in 1995. Statistical treatments of these data are restricted to $95 \%$ confidence limits (density of hosts, Figure 4B) and the Z-test (Snedecor \& Cochran, 1989) when dealing with parasite prevalence (part of Figure $4 \mathrm{~A}$, see below). When evaluating trends in infection intensity (Figure 4C), the non-parametric MannWhitney test has been applied rather than $95 \%$ confidence limits, due to the overdispersed distribution of parasites within the amphipods. For convenience, ordi- 


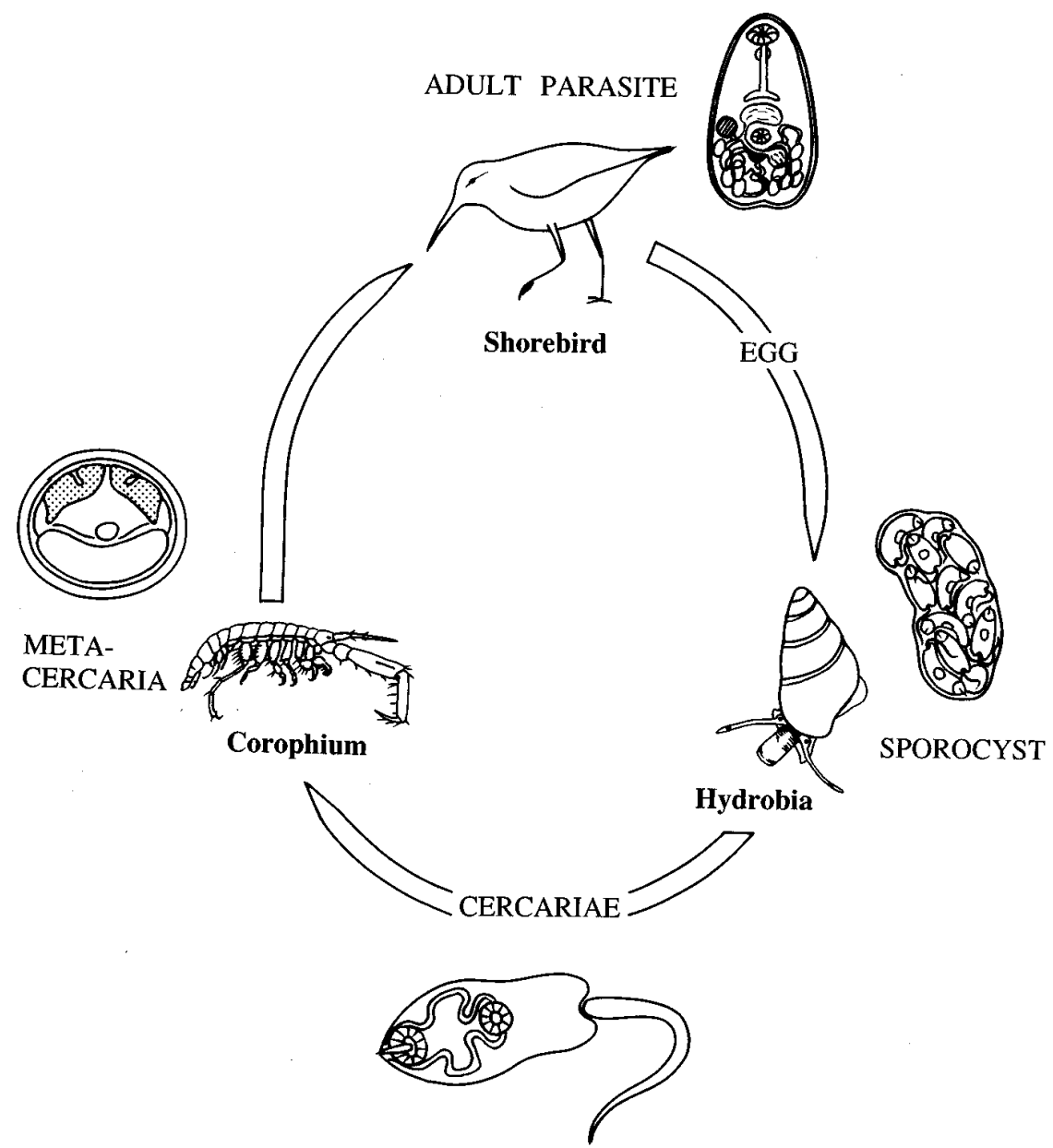

Figure 1. The life cycle of the microphallid trematodes Maritrema subdolum and Microphallus claviformis. See text for details.

nary standard error of the mean is nevertheless shown in the figure.

Figure 4A, showing the temporal development in density of infected hosts, is based on mean host density multiplied by trematode prevalence. Since the latter is obtained from a subsample, the statistical significance of the observed changes can not be tested formally. However, if both mean host density and trematode prevalence show similar and statistically significant trends, or when one of those parameters shows no significant trend whereas the other one does, it is reasonable to consider an observed change in the density of infected hosts to be significant. In Figure 4A such significant changes are indicated by an asterisk.

Indication of the main periods of bird presence at the study site is based on own bird counts in the area in concert with data presented by Laursen \&
Frikke (1984). Temperature data originate from a nearby meteorological station.

In Figure 5 the mean densities of hosts are shown without attached variation in order to simplify the figure. The statistical significance (using one-way ANO$\mathrm{VA}$ and Z-test) of any trends mentioned is, however, indicated in the figure legend.

All statistical tests are two-tailed, using the default $5 \%$ level of significance.

\section{Results and discussion}

\section{The phenology}

Considering the microphallid life cycle (Figure 1) it is possible to make at least four obvious predic- 


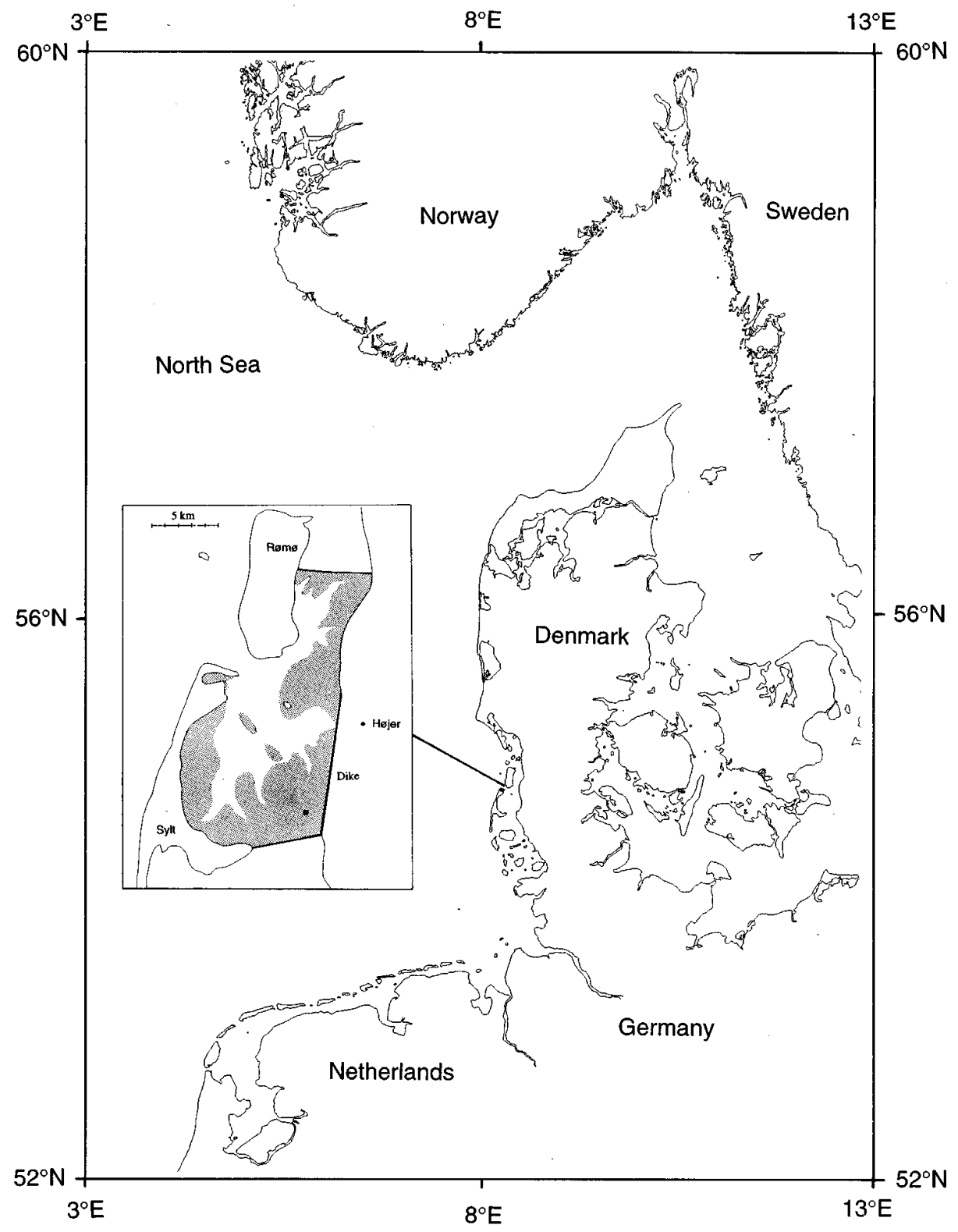

Figure 2. The location of the study site in the Danish Wadden Sea Rømø and Sylt) on the inserted map (shaded areas).

tions regarding the phenology of these parasites within their intermediate host populations. Firstly, the abundance of microphallids in the amphipods should depend on the density of infected Hydrobia, which in turn is dependent on former bird presence. Secondly, their occurrence in Corophium should lag behind their occurrence in Hydrobia because it may take about 1-1.5 month before these parasites reach matu- rity within the snail host (Jensen \& Mouritsen, 1992). Thirdly, the occurrence of metacercariae within the amphipods should increase as ambient temperatures rise due to a positive association between temperature and cercarial emergence. In experiments, we showed that the number of shed Maritrema-cercariae increased by a factor of nine as the water temperature rose from $15{ }^{\circ} \mathrm{C}$ to $25^{\circ} \mathrm{C}$ (Mouritsen \& Jensen, 


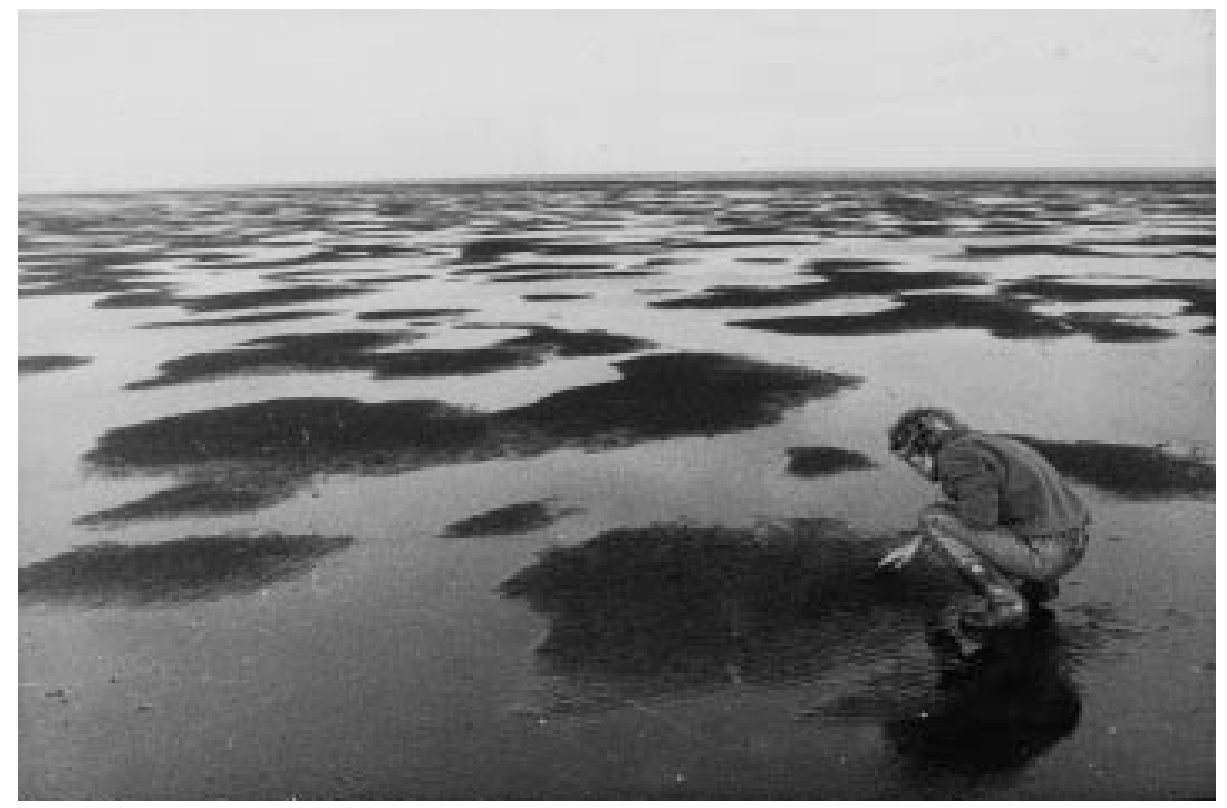

Figure 3. A view of a well-developed Corophium-bed at Højer tidal flat in the southern part of the Danish Wadden Sea.

1977; see also Ginetsinkaya, 1988). Fourthly, the size of the microphallid metapopulation within the amphipod hosts should also depend on the amphipod density itself. This should occur, not because of the usual expectation of density dependence due to e.g. malnutrition causing the infective stages to transmit more readily (e.g. Anderson, 1991 and references therein), but simply because more hosts may be able to absorb more of the released cercariae. The microphallid cercariae become exhausted after approximately six hours, and if they fail to find a suitable host within this period they will die (K. N. Mouritsen, unpubl. data).

The above predictions are fully confirmed by our results. During spring a decline in density of infected Hydrobia and Corophium is observed (Figure 4A), corresponding to a decrease in the density of these hosts in general (Figure 4B). These changes are most likely due to bird predation which is quite intensive during spring. The most numerous shorebird species at our study site, Dunlins, prey on both Corophium and Hydrobia (Worrall, 1984; Mouritsen, 1994), and it has previously been shown that shorebirds are capable of diminishing prey abundance, including Corophium, significantly (e.g. Wilson, 1991; Peer et al., 1986).

Following the spring migration period of the birds, a considerable and rapid increase in the density of microphallid infected snails to about 1000 specimens $\mathrm{m}^{-2}$ in early June is observed (Figure 4A). This increase should be seen as a consequence of the previous presence of birds giving rise to new infections via transmission of microphallid eggs from their droppings to the snails. In support of this interpretation no more new infections appear during the summer period in which migratory shorebirds are absent. Regarding the density of infected amphipods, a considerable peak of about 40000 infected specimens $\mathrm{m}^{-2}$ can be observed in mid August. Hence, almost half of the entire Corophium population is infested with microphallid trematodes just before the shorebirds return during their autumn migration.

As predicted there is a time lag between the increase in density of infected snails and infected amphipods (Figure 4A). Three points should sufficiently explain this pattern. During spring and especially summer a significant increase in the abundance of amphipods in general is observed, which can be ascribed to two recruitment periods (Figure 4B). From April to May the proportion of Corophium individuals larger than three $\mathrm{mm}$ (the approximate size from which the amphipods can be sexed by the presence of oostegites) shows a decline from $89 \%$ to $38 \%$. A similar trend is observed from June to August, where the proportion of the larger specimens is reduced from $50 \%$ to $28 \%$. In conclusion, the population of amphipods increases during the summer, and more specimens will catch up the released microphallid cercariae. The larval trematodes do not 

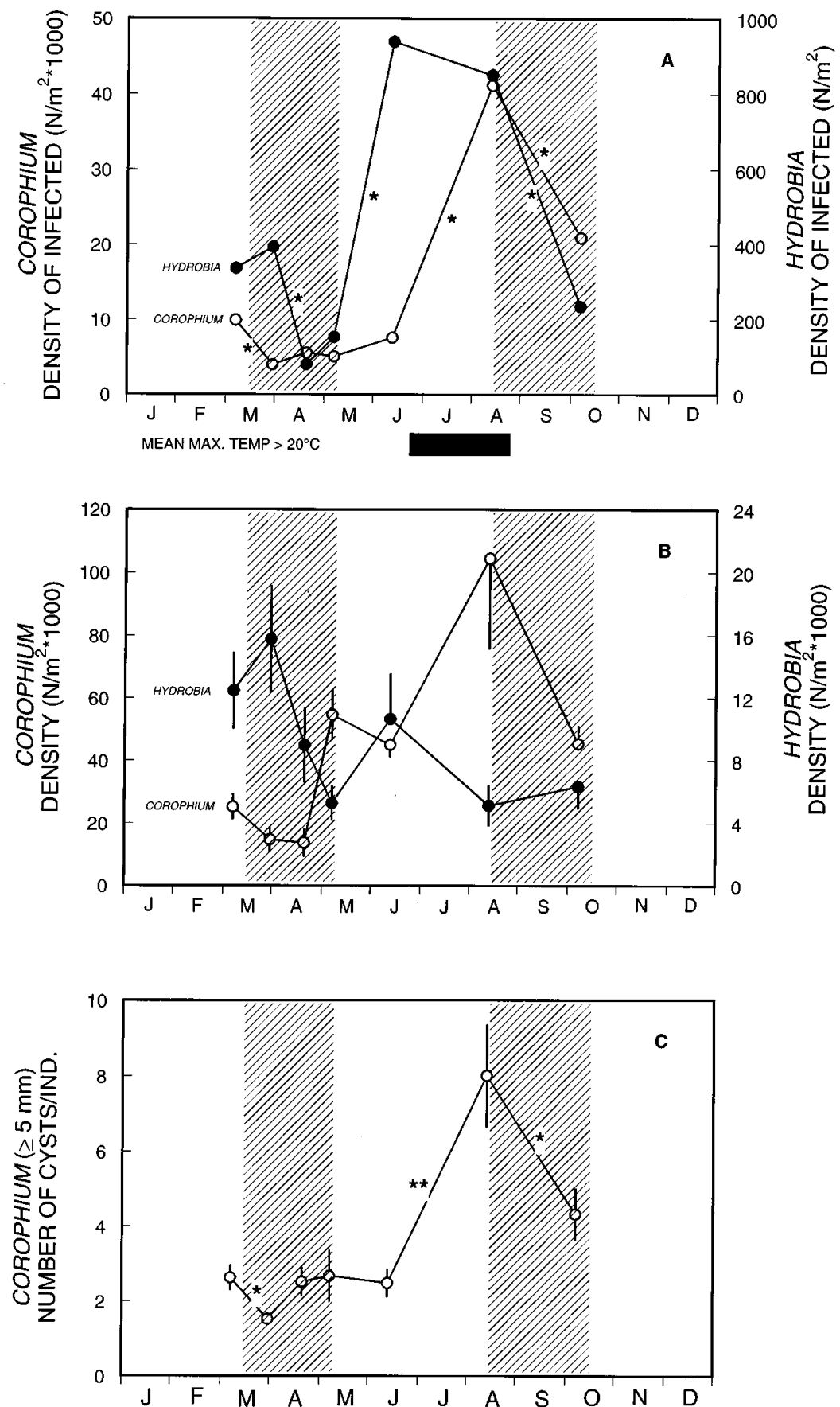

Figure 4. The phenology of hosts and parasites from spring to autumn 1995 on Højer tidal flat. Shaded areas denote the principal periods of wader presence. A: The seasonal changes in the density (numbers $\mathrm{m}^{-2}$ ) of microphallid infected Hydrobia ulvae and Corophium volutator. The black bar below the $\mathrm{x}$-axis shows the period in which the weekly mean of daily maximum temperature exceeded $20^{\circ} \mathrm{C}(*$ denotes changes that can be considered significant; see Materials and Methods). B: The population dynamics of the Hydrobia and Corophium host (mean density $\mathrm{m}^{-2} \pm 95 \%$ confidence limits). C: Changes in the mean number $( \pm$ S.E. $)$ of microphallid trematodes within infected amphipod individuals ( $n=19-39$ Corophium specimens). $* p<0.05$ (Mann-Whitney test, $\mathrm{Z}>2.01), * * p<0.001$ (Mann-Whitney test, $\mathrm{Z}=3.74$ ). 


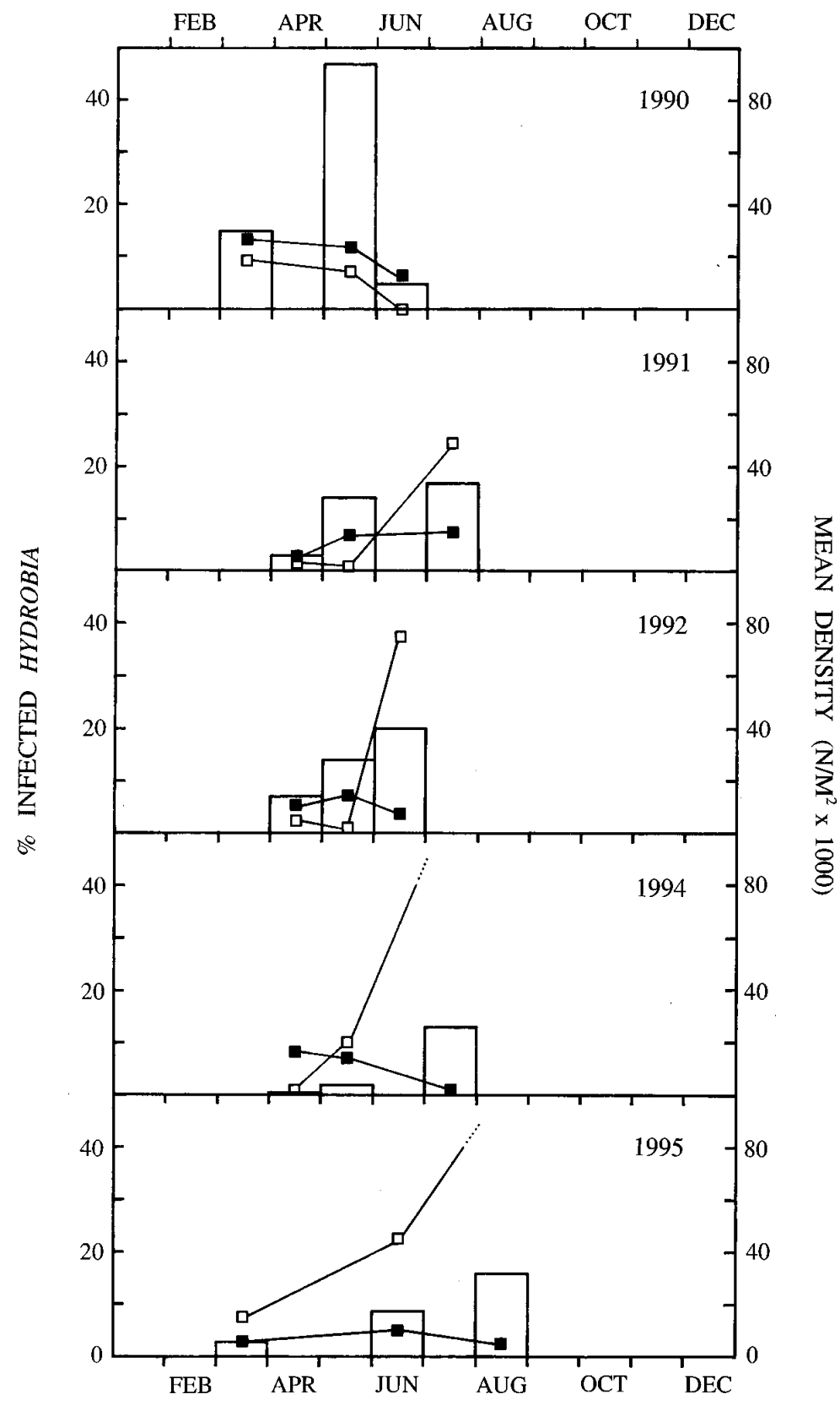

Figure 5. The mean density $\mathrm{m}^{-2}$ of Hydrobia $(\mathbf{\square})$ and Corophium $(\square)$, and the prevalence (\%) of microphallid infections within the snail population (white bars) at three sampling occasions in spring and summer 1990-95. A dotted line indicates that the density is outside the range of the y-axis. During all years, the general trends of increase (decrease in 1990) in the amphipod population are statistically significant (One-way ANOVA, $\mathrm{F}>23.6, p<0.001$ ). Also the changes in parasite prevalence from the first to the third sampling event in the years 1991-95 and between all three sampling events in 1990 are significant (Z-test, $\mathrm{Z}>1.95, p<0.05$ ).

seek out their host actively, but rely mainly on passive transport via the ventilation current of the amphipods to obtain contact (Mouritsen \& Jensen, 1997). The increase in host abundance especially during late sum- mer is not, however, the sole explanation for the time lag. As it appears from Figure $4 \mathrm{C}$, there is a significant increase from June to August in the infection intensity of the larger Corophium specimens, indicating that 
also the rate of cercariae transmission increases during this period. This is likely due to the coincident elevation of ambient temperatures (Figure 4A) causing an accelerated shedding of cercariae from the snail hosts. The final and additional explanation of the time lag is related to the development time of the larval trematodes within the snails. Although a high prevalence of trematode infected snails was observed already in early June, not all infections were mature and therefore not ready for transmission. Although the above explanations are not mutually exclusive, we expect that the rise in temperature during late summer is the most important factor contributing to the observed time lag.

During autumn (August-October) the density of both the infected first and the secondary intermediate hosts, the abundance of amphipods in general, and the infection level of Corophium decrease (Figure 4). The decline in amphipod density, infected or uninfected, should readily be explained by bird predation. Decreasing temperatures during autumn probably reduce the transmission of cercariae from snails to amphipods significantly, contributing to a lower infection level in the latter. A decline in the density of infected Hydrobia (Figure 4A) further enforces this trend. The similar trend in the parasite level of the larger amphipod specimens (Figure 4C) may also be explained by a lowered transmission rate, by predation (the larger individuals are most attractive to feeding birds (Peer et al., 1986) and usually harbour most parasites (Bick, 1994)), and by growth of smaller and less infected individuals into the larger size class. In conclusion, most of the changes of the amphipod population can be attributed to the presence of very high numbers of feeding shorebirds in the study area (not only the adult birds, but also their offspring pass through the Wadden Sea during the autumn migration period) and lower ambient temperatures.

However, the observed autumn decline in the density of infected Hydrobia, though the abundance of snails in general seems to be steady (Figure 4B), is a most intriguing result. Following a period of high bird presence, the density of infected snails would at least be expected to remain unaltered. The reason may be that the Danish Wadden Sea is the first main stopover during the birds' autumn migration (Smit \& Piersma, 1989). Hence, the birds arrive from basically terrestrial breeding habitats and can therefore not yet be expected to harbour many marine trematodes; the parasites persist for only a few weeks in the bird host before they are lost. Accordingly, no trematode eggs are probably expelled through the droppings of the birds during autumn and consequently no new infections can be expected to accumulate. More speculations include: (1) Infected snails show changed behaviour (Mouritsen \& Jensen, 1994) perhaps making them more subjected to bird predation than uninfected specimens (Dobson, 1988), (2) since it has been shown that infected snails may be less resistant to unfavourable abiotic conditions (e.g. Tallmark \& Norrgren, 1976; Huxham et al., 1993; Sousa \& Gleason, 1989; Jensen et al., 1996), infected specimens may experience a higher mortality rate than uninfected, and (3) infected snails may die off following intensive cercariae emission (Dobson, 1988; Jensen \& Mouritsen, 1992). Additional possibilities could be imagined, but an exhaustive discussion is out of the scope of this paper.

\section{Consequences for population dynamics}

The results show that microphallid trematodes are rather successful in completing their complex life cycle. However, if the parasite level is sufficiently high, they are also able to kill their secondary intermediate host before trophic transmission is accomplished, and hence, the parasites may be expected to affect the population dynamics of the amphipods. By experimental infection of Corophium volutator with microphallids, we found that those individuals that died during the treatment harboured on average 22 metacercariae each, whereas the surviving (and infected) specimens contained only 12 cysts (Jensen, 1996). Considering 22 metacercariae as a kind of lethal level, the maximum of about six cysts per amphipod specimen found in the largest animals of the samples from August 1995 (Figure 4C) does not suggest any obvious parasite-induced mortality. Although some regulation in the sense of May and Anderson's theoretical framework (Anderson, 1991 and references therein) on the Corophium population may occur (individuals harbouring more metacercariae might have died off before sampling), no significant reduction in the abundance of Corophium can be ascribed to the direct effect of parasites in 1995.

Similar conclusions can be drawn for the years 1991, 1992 and 1994 which resemble quite well the situation in 1995 (Figure 5). The general picture is a gradual and significant increase in the prevalence of microphallid trematodes within the snail population during spring and summer, reaching about $20 \%$ at the most. During the same period significant increases also in the density of Corophium due to recruitment have been observed. However, 1990 was different. That 
year the parasite prevalence in the snail population increased rapidly already in spring reaching close to $50 \%$ in May, and the parasites had almost disappeared in June. The high microphallid prevalence in May corresponds to a density of infected Hydrobia of about $12000 \mathrm{~m}^{-2}$, a number that should be compared with $1000 \mathrm{~m}^{-2}$ in August 1995 (Figure 4A). During the same period the whole amphipod population vanished, and from further three sampling occasions in autumn and winter 1990 (data not shown) we know that the population of Corophium did not recover until spring 1991. Beside these changes in population dynamics of both host and parasites, 1990 was also unusual regarding spring temperatures. Compared with a ten year temperature-normal, the ambient temperatures in spring 1990 were several degrees higher and reached a maximum of $26^{\circ} \mathrm{C}$ already in the beginning of May (see Jensen \& Mouritsen, 1992 for details). We therefore suggested that the population crash in Corophium was a result of the high prevalence of microphallid trematodes in the Hydrobia population in concert with unusually high ambient temperatures causing a mass transmission of cercariae from snails to amphipods, eventually driving the population of the latter extinct. This interpretation is strongly supported by a laboratory experiment showing that microphallid trematodes are able to induce a mortality of above $50 \%$ in comparison with a control during nine days of experimentation under 1990 in situ conditions (Mouritsen \& Jensen, 1997). As emphasized in the introduction, many reasons can be given why a species should show wide fluctuations in abundance other than parasites. However, as argued in detail elsewhere (Jensen \& Mouritsen, 1992), most conceivable factors causing significant mortality in an intertidal infaunal amphipod species, including e.g. predation, strong off- or onshore winds, anoxic sediment conditions, were absent or insignificant in May and June 1990.

Besides our observation in 1990, previous studies have also reported on sudden decline or even local extinction of Corophium populations in which parasites have been, or could be, suspected to be the causative mortality agent (Segerstråle, 1960; Muus, 1967; Möller \& Rosenberg, 1982; Reise, 1985; Ólafsson \& Persson, 1986). But parasite-induced mass mortality in Corophium, however, does not seem to be an annual event, as it also appears from Figure 5. The underpinning reason for the mortality in 1990 should be found in the concurrence of unusually high temperatures and parasite prevalence in the snails. The high temperatures may have been responsible not only for the transmission of cercariae, but also for an accelerated egg-to-snail transmission and cercariae development within the snails, giving rise to the unexpected high spring prevalence of parasites in the snail population. It is also possible that the shorebirds feeding at our study site in spring 1990 were unusually highly infected, and hence, supplied the tidal flat with high numbers of infective trematode eggs. The reason for the latter possibility should probably be sought in the birds' wintering areas.

\section{Conclusions}

The metapopulations of microphallid trematodes within their intermediate hosts show profound seasonal patterns. They decrease during spring and autumn and increase during the summer period. The occurrence of the parasites in the secondary intermediate hosts is time delayed in relation to their occurrence in the first intermediate host population. An intimate interplay of factors is responsible for this scenario, including predation by the shorebird final hosts, the ambient temperatures and the development time of infective larval trematodes within the Hydrobia snails. Hence, the microphallid life cycle does not seem to be completed within a single season (spring or autumn) in which all three hosts occur together, but runs mainly in three steps separated in time: (1) transmission of trematode eggs to snails during spring, (2) transmission of cercariae to the amphipods during summer, and (3) trophic transmission of metacercaria-infected Corophium to the birds during autumn.

Microphallids may occasionally give rise to high mortality in the secondary intermediate host population. The prerequisites for this to happen in the Danish Wadden Sea apparently imply a high parasite prevalence in the mud snail population in addition to high ambient temperatures (at least above $20^{\circ} \mathrm{C}$ ).

\section{Acknowledgments}

We are grateful to Lone Thybo Mouritsen for reading an earlier version of the manuscript. The work has been supported financially by the Carlsberg Foundation. Meteorological data were kindly provided by the Danish Meteorological Institute. 


\section{References}

Ambrose, W. G. J., 1991. Are infaunal predators important in structuring marine soft-bottom communities. Am. Zool. 31: 849-860.

Anderson, R. M., 1991. Populations and infectious diseases: ecology or epidemiology? J. anim. Ecol. 60: 1-50.

Barnes, R. S. K. \& R. N. Hughes, 1988. An introduction to marine ecology. Black. Sci. Publ., Oxford, 351 pp.

Bick, A., 1994. Corophium volutator (Corophiidae: Amphipoda) as an intermediate host of larval digenea - an ecological analysis in a coastal region of the southern Baltic. Ophelia 40: 27-36.

Deblock, S., 1980. Inventaire des trematodes larvaires parasites des mollusques Hydrobia (Prosobranches) des côtes de France. Parasitologia 22: 1-105.

Dobson, A. P., 1988. The population biology of parasite-induced changes in host behaviour. Quat. Rev. Biol. 63: 139-165.

Dobson, A. P. \& P. J. Hudson, 1986. Parasites, disease and the structure of ecological communities. TREE 1: 11-15.

Ginetsinskaya, T. A., 1988. Trematodes, their Life Cycles, Biology and Evolution. Dr Indira Kohli (translator), Amerind Publishing Co. Pvt. Ltd., New Delhi, 559 pp.

Holt, R. D., 1993. Infectious diseases of wildlife, in theory and in practice. TREE 8: 423-425.

Huxham, M., D. Raffaelli \& A. Pike, 1993. The influence of Cryptocotyle lingua (Digenea: Platyhelminthes) infections on the survival and fecundity of Littorina littorea (Gastropoda: Prosobranchia); an ecological approach. J. exp. mar. Biol. Ecol. 168: 223-238.

Jensen, T., 1996. The influence of microphallid trematodes on their host organisms Corophium volutator and Corophium arenarium. Ms. thesis, University of Aarhus, Denmark.

Jensen, K. T., G. Latama \& K. N. Mouritsen, 1996. The effect of larval trematodes on the survival rates of two species of mud snails (Hydrobiidae) experimentally exposed to desiccation, freezing and anoxia. Helgol. Meeresunters. 50: 327-335.

Jensen, K. T. \& K. N. Mouritsen, 1992. Mass mortality in two common soft-bottom invertebrates, Hydrobia ulvae and Corophium volutator - the possible role of trematodes. Helgol. Meeresunters. 46: 329-339.

Kinne, O., 1980. Diseases of marine animals: General aspects. In Kinne, O. (ed.), Diseases of Marine Animals. Vol. 1. Wiley, New York: $13-73$

Lauckner, G., 1987. Effects of parasites on juvenile Wadden Sea invertebrates. In Tougaard, S. \& S. Asbirk (eds), Proceedings of the 5th International Wadden Sea Symposium. The National Forest and Nature Agency and the Museum of Fisheries and Shipping, Esbjerg, Denmark: 103-121.

Laursen, K. \& J. Frikke, 1984. The Danish Wadden Sea. Cambridge University Press, Cambridge: 214-223.

Minchella, D. J. \& M. E. Scott, 1991. Parasitism: A cryptic determinant of animal community structure. TREE 6: 250-253.

Mouritsen, K. N., 1994. Day and night feeding in Dunlins Calidris alpina: choice of habitat, foraging technique and prey. J. Avian Biol. 25: 55-62.
Mouritsen, K. N. \& K. T. Jensen, 1994. The enigma of gigantism: effect of larval trematodes on growth, fecundity, egestion and locomotion in Hydrobia ulvae (Pennant) (Gastropoda: Prosobranchia). J. exp. mar. Biol. Ecol. 181: 53-66.

Mouritsen, X. N.\& K. T. Jensen, 1997. Parasite transmission between soft-bottom invertebrates: temperature mediated infection rates and mortality in Corophium volutator. Mar. Ecol. Prog. Ser. 151: 123-134.

Muus, B., 1967. The fauna of Danish estuaries and lagoons. Distribution and ecology of dominating species in the shallow reaches of the mesohaline zone. Meddr. Danm. Fisk. og Havunders., 316 pp.

Möller, P. \& R. Rosenberg, 1982. Production and abundance of the amphipod Corophium volutator on the west coast of Sweden. Neth. J. Sea Res. 16: 127-140.

Nybakken, J. W., 1993. Marine Biology. An Ecological Approach. Harper Collins College Publishers, New York, 462 pp.

Olafsson, E. B. \& L. E. Persson, 1986. The interaction between Nereis diversicolor O. F. Mueller and Corophium volutator Pallas as a structuring force in a shallow brackish sediment. J. exp. mar. Biol. Ecol. 103: 103-117.

Peer, D. L., L. E. Linkletter \& P. W. Hicklin, 1986. Life history and reproductive biology of Corophium volutator (Crustacea: Amphipoda) and the influence of shorebird predation on population structure in Chignecto Bay, Bay of Fundy, Canada. Neth. J. Sea Res. 20: 359-373.

Posey, M. H., 1987. Influence of relative variabilities on the composition of benthic communities. Mar. Ecol. Prog. Ser. 39: 99-104.

Reise, K., 1985. Tidal Flat Ecology. An Experimental Approach to Species Interactions. Springer-Verlag, Berlin, $191 \mathrm{pp}$.

Segerstråle, S. G., 1960. Fluctuations in the abundance of benthic animals in the Baltic area. Soc. Scient. Fenn., Comment. Biol. 23: $1-19$.

Smit, C. J. \& T. Piersma, 1989. Numbers, midwinter distribution, and migration of wader population using the east atlantic flyway. IWRB Special Publication No. 9, Canadian Wildlife Service, Ottawa: 24-63.

Snedecor, G. \& W. G. Cochran, 1989. Statistical Methods. Iowa State University Press, Ames, Iowa, 503 pp.

Sousa, W. P., 1991. Can models of soft-sediment community structure be complete without parasites? Am. Zool. 31: 821-830.

Sousa, W. P. \& M. Gleason, 1989. Does parasitic infection compromise host survival under extreme environmental conditions? The case for Cerithidea californica (Gastropoda: Prosobranchia). Oecologia 80: 456-464.

Tallmark, B. \& G. Norrgren, 1976. The influence of parasitic trematodes on the ecology of Nassarius reticulatus (L.) in Gullmar Fjord (Sweden). Zoon 4: 149-154.

Wilson, W. H., 1991. Competition and predation in marine softsediment communities. Ann. Rev. Ecol. Syst. 21: 221-241.

Worrall, D. H., 1984. Diet of the dunlin Calidris alpina in the Severn Estuary. Bird Study 31: 203-212. 